\title{
Kinetics, Physical-Chemical Characterization and Antioxidant Activity of One-Pot Green Synthesized Noble Metallic Nanoparticles ${ }^{\dagger}$
}

\author{
Ana-Alexandra Sorescu 1,2,*, Alexandrina Nuță 1,3, Rodica-Mariana Ion ${ }^{1,2}$ and \\ Mădalina Elena David 1,2 \\ 1 The National Research \& Development Institute for Chemistry and Petrochemistry -ICECHIM, 202 \\ Splaiul Independentei, $6^{\text {th }}$ district, 060021 Bucharest, Romania; alexnuta1256@yahoo.com (A.N.); \\ rodica_ion2000@yahoo.co.uk (R.-M.I.); madalina.e.david@gmail.com (M.E.D.) \\ 2 Valahia University, $13^{\text {th }}$ Sinaia Alley, 130004 Targoviste, Dambovita, Romania \\ 3 The Romanian Academy “Stefan S. Nicolau” Institute of Virology, 285 Mihai Bravu Avenue, $3^{\text {rd }}$ district, \\ 030304 Bucharest, Romania \\ * Correspondence: anaalexandrasorescu@yahoo.com or ana-alexandra.sorescu@icechim.ro; \\ Tel.: +40-722-305-814 \\ † Presented at 1st International Electronic Conference on Applied Sciences, 10-30 November 2020; Available \\ online: https://asec2020.sciforum.net/.
}

Published: 10 November 2020

\begin{abstract}
Metallic nanoparticles, due to their reduced size and high surface area, have unique properties that facilitate their application, with excellent results, in various scientific fields and allows an easy functionalization of their surface with a variety of ligands. Noble metallic nanoparticles play a special role in nanomedicine due to their proved antibacterial, antifungal and strong antioxidant activity. These metallic nanoparticles can be prepared using both conventional and unconventional routes and, in the last decades, the methods involving plants and their aqueous extracts are constantly and successfully replacing expensive and time-consuming conventional chemical methods. This paper describes the one-pot green synthesis of silver nanoparticles (AgNPs) and gold nanoparticles (AuNPs) from aqueous plant extracts and corresponding metallic salts under different time and temperature conditions. Both silver and gold nanoparticles are green synthesized from plants with important pharmacological benefits to human health: Hyssop (Hyssopus officinalis), European goldenrod (Solidago virgaurea) and Knotgrass (Polygonum aviculare) and their synthesis is monitored by recording the UV-Vis spectra at specific time intervals: $0 \mathrm{~s}, 5$ $\mathrm{min}, 15 \mathrm{~min}, 30 \mathrm{~min}, 1 \mathrm{~h}$ and $24 \mathrm{~h}$ in order to evaluate their stability in time. FTIR spectra were used for the specific determination of functional groups and DLS was used to determine the nanometer scale of the particles. Also, antioxidant activity was evaluated using the DPPH method for both silver and gold nanoparticles and compared to that of the crude aqueous extracts.
\end{abstract}

Keywords: silver nanoparticles; gold nanoparticles; green synthesis; plants; kinetics

\section{Introduction}

Nanotechnology is constantly and rapidly detaching as one of the most promising technologies that allows numerous applications in various areas of material science. Metallic nanoparticles are an important result of nanotechnology and their versatile properties and applications attracted researchers all over the world. In the last two decades, noble metallic nanoparticles, especially silver nanoparticles (AgNPs) and gold nanoparticles (AuNPs) have received worldwide attention due to their numerous applications in the biomedical and physiochemical fields [1]. 
Synthesizing AgNPs and AuNPs using microorganisms and especially different plants and plant parts (e.g.,: stem, bark, seeds, flowers, etc.) has been extensively studied and has, therefore, been recognized as an efficient alternative route that properly allows obtaining affordable and reproductible noble metallic nanoparticles [2]. Silver nanoparticles (AgNPs) and gold nanoparticles (AuNPs), due to their antibacterial, antioxidant and antifungal properties, exhibit multiple applications in medicine, different industry branches, biology, etc. [3,4].

Green synthesis of noble metallic nanoparticles, especially plant-mediated one, is a cheap, facile and environmentally friendly approach. Not only does it eliminate the use of hazardous chemicals but also allows an active coating of biological moieties on the surface of the metallic nanoparticles [5]. An extremely important aspect is that these route uses only water as a reducing medium, therefore eliminating human exposure to toxic agents [6]. Also, a very important characteristic is that all the phytocompounds play a major part in the reduction and stabilization of the one-pot green synthesized noble metallic nanoparticles.

Hyssop (Hyssopus officinalis) is used in traditional herbal medicine for its antiseptic, expectorant and cough reliever benefits due to its rich content in cineol, camphor, diosmin, hesperidin and rosmarinic acid. Hyssop tea has been used since ancient times both as medicine as well as an internal cleanser, being considered, in Biblical times, as a holy tea [7]. European goldenrod (Solidago virgaurea), also an important representative of traditional medicine, is often used to supplement urinary tract's health, to ease the inflammation process (due to its rich content in flavonoids), etc. [8]. Knotgrass (Polygonum aviculare), a plant that can be found in almost all regions, is collected in Eastern Europe for medicinal purposes, in the treatment of bronchitis and various respiratory problems [9].

This paper describes the one-pot green synthesis of silver and gold nanoparticles from aqueous plant extracts and corresponding metallic salts (silver nitrate and tetrachloauric acid) following different reaction conditions. Both silver and gold nanoparticles are green synthesized from plants with significant benefits in traditional medicine: Hyssop (Hyssopus officinalis), European goldenrod (Solidago virgaurea) and Knotgrass (Polygonum aviculare) and their synthesis is monitored by recording the UV-Vis spectra at well-determined time intervals: $0 \mathrm{~s}, 5 \mathrm{~min}, 15 \mathrm{~min}, 30 \mathrm{~min}, 1 \mathrm{~h}$ and $24 \mathrm{~h}$ in order to evaluate their stability in time. FTIR spectra were used to determine different functional groups and DLS allowed a proper determination of the nanometer scale of the green-synthesized particles. Also, antioxidant activity was evaluated using the DPPH method for both silver and gold nanoparticles and compared to that of the aqueous extracts.

\section{Materials and methods}

\subsection{Materials}

Tetrachloauric acid $\left(\mathrm{HAuCl}_{4}\right), \mathrm{DPPH}$, (2,2-diphenyl-1-picryl-hydrazyl-hydrate stable free radical) and tetrachloauric acid $\left(\mathrm{HAuCl}_{4}\right)$ were purchased from Sigma-Aldrich. Ethanol $\left(\mathrm{C}_{2} \mathrm{H}_{5} \mathrm{OH}\right)$ was purchased from Scharlau and silver nitrate $\left(\mathrm{AgNO}_{3}\right)$ from ChimReactiv. The distilled water was daily prepared in our laboratory. Hyssop (Hyssopus officinalis), European goldenrod (Solidago virgaurea) and Knotgrass (Polygonum aviculare) were acquired from the local Plafar shop.

\subsection{Preparation of aqueous plant extracts}

Hyssop (Hyssopus officinalis), European goldenrod (Solidago virgaurea) and Knotgrass (Polygonum aviculare) were purchased ready dried and used to prepare the aqueous extracts as follows:

- $25 \mathrm{~g}$ dried plant were weighted, transferred into an extractor and, to that, $250 \mathrm{~mL}$ distilled water were added;

- the heterogenous mixture was left $24 \mathrm{~h}$, at $4{ }^{\circ} \mathrm{C}$ (in a refrigerator) to infuse in order to release all the active components;

- the resulted mixtures were filtered until a clear aqueous extract were obtained. 


\subsection{One-Pot Green Synthesis of Noble Metallic Nanoparticles}

An aqueous $10^{-3} \mathrm{M}$ solution of metalic salt-e.g.,: silver nitrate $\left(\mathrm{AgNO}_{3}\right)$ for $\mathrm{AgNPs}$ and tetrachloroauric acid $\left(\mathrm{HAuCl}_{4}\right)$ for AuNPs, was freshly prepared and used for the green synthesis of AgNPs/AuNPs from Hyssop (Hyssopus officinalis), European goldenrod (Solidago virgaurea) and Knotgrass (Polygonum aviculare) by mixing $5 \mathrm{~mL}$ aqueous extracts with $50 \mathrm{~mL} \mathrm{10^{-3 }} \mathrm{M}$ metalic salt aqueous solution. In the present research, two different reaction conditions were used for both green synthesized noble metallic nanoparticles:

- at room temperature, in the dark for $24 \mathrm{~h}$ with no stirring and

- at $50{ }^{\circ} \mathrm{C}$, under a continuous stirring of $600 \mathrm{rpm}$ for $30 \mathrm{~min}$, then the heat was turned off and the stirring was maintained for an adittional $30 \mathrm{~min}$.

Regardless of the reaction conditions used for the green synthesis of both AgNPs and AuNps, finally, the reaction mixtures were ultrasonicated at $100 \mathrm{rpm}$, at $50{ }^{\circ} \mathrm{C}$, for $5 \mathrm{~min}$ in order for the solutions to homogenize properly.

\subsection{Characterization methods}

The absorption spectra for Hyssopus (Hyssopus officinalis), European goldenrod (Solidago virgaurea) and Knotgrass (Polygonum aviculare) aqueous extract and noble metallic nanoparticles thereof were recorded using a M 400 Carl Zeiss Jena UV-Vis spectrometer in the wavelength range of 250-800 nm. The on-pot green synthesis of AgNPs and AuNPs at $50{ }^{\circ} \mathrm{C}$ was caaried out using a RSM-10HS Phoenix Instrument magnetic stirrer fully equipped. The ultrasonic bath used was Bioblock Scientific.

Fourier transform infrared spectroscopy (FTIR) determinations were done using a Vertex 80 FTIR spectrometer with high-resolution Hyperion 3000 microscope, in the range of $8000-400 \mathrm{~cm}^{-1}$. Dynamic light scattering (DLS) spectra were recorded using a Zetasizer Nano SZ-Malvern instrument.

Antioxidant activity for Hyssop (Hyssopus officinalis), European goldenrod (Solidago virgaurea) and Knotgrass (Polygonum aviculare) aqueous extract, AgNPs and AuNPs was evaluated using the DPPH (2,2-diphenyl-1-picryl-hydrazyl-hydrate stable free radical) method: a DPPH solution was prepared in ethanol and $0.5 \mathrm{~mL}$ aqueous plant extract was mixed with $1 \mathrm{~mL} 0.02 \mathrm{mg} / \mathrm{mL}$ DPPH solution. The solutions were tested by recording the absorbances at $517 \mathrm{~nm}$. A blank sample was prepared in parallel by mixing $0.5 \mathrm{~mL}$ distilled water with $1 \mathrm{~mL} 0.02 \mathrm{mg} / \mathrm{mL}$ DPPH solution and the spectrum was recorded at the same wavelength $[10,11]$.

The antioxidant activity (AA \%) was according to the following formula:

$$
\text { AA } \%=[(\text { Acontrol }- \text { Asample }) / \text { Acontrol }] \times 100
$$

- Acontrol is the absorbance of the blank DPPH solution and

- Asample represents the absorbance Hyssop (Hyssopus officinalis), European goldenrod (Solidago virgaurea) and Knotgrass (Polygonum aviculare) aqueous extracts mixed with $0.02 \mathrm{mg} / \mathrm{mL}$ DPPH solution.

\section{Results and discussions}

\subsection{Ultraviolet-Visible (UV-Vis) Results}

UV-Vis spectra were recorded for all three aqueous extracts and the corresponding noble metallic nanoparticles in the range of $210-800 \mathrm{~nm}$. A general characterisitc id that all the absorptions recorded at about $270 \mathrm{~nm}$ and $370 \mathrm{~nm}$ for all the three aqueous extracts can be designated to phenolic acids and their functional derivatives (flavones, quinones) (Table 1). 
Table 1. UV-Vis absorptions for aqueous extracts.

\begin{tabular}{ccc}
\hline Aqueous Extract & Phenolic Acids & Flavonoids \\
\hline Hyssop (Hyssopus officinalis) & $272 \mathrm{~nm}$ & $367 \mathrm{~nm}$ \\
\hline European goldenrod (Solidago virgaurea) & $274 \mathrm{~nm}$ & $370 \mathrm{~nm}$ \\
\hline Knotgrass (Polygonum aviculare) & $270 \mathrm{~nm}$ & $373 \mathrm{~nm}$ \\
\hline
\end{tabular}

The bioreduction of silver and gold ions is initially observed as a result of the visual change in color of the resulted colloidal solutions of AgNPs and AuNPs and is further highlighted by the UVVis spectra. Usually, the maximum absorptions for AgNPs are between 432-457 nm (Table 2) and for AuNPs are in the region of 520-550 nm (Table 3). The colour for AgNPs varies from light brown to dark brown (taking into account the size of the green synthesized AgNPs) and for AuNPs from cherry red to violet red respectively.

Table 2. UV-Vis absorptions for the green synthesized AgNPs.

\begin{tabular}{ccc}
\hline Aqueous Extract & $\begin{array}{c}\text { AA (\%) AgNPs Room } \\
\text { Temperature }\end{array}$ & $\begin{array}{c}\text { AA (\%) AgNPs 50 } \\
{ }^{\circ} \mathbf{C}\end{array}$ \\
\hline Hyssop (Hyssopus officinalis) & $432 \mathrm{~nm}$ & $448 \mathrm{~nm}$ \\
\hline $\begin{array}{c}\text { European goldenrod (Solidago } \\
\text { virgaurea) }\end{array}$ & $448 \mathrm{~nm}$ & $450 \mathrm{~nm}$ \\
\hline Knotgrass (Polygonum aviculare) & $453 \mathrm{~nm}$ & $457 \mathrm{~nm}$ \\
\hline
\end{tabular}

Table 3. UV-Vis absorptions for the green synthesized AuNPs.

\begin{tabular}{ccc}
\hline Aqueous Extract & $\begin{array}{c}\text { AA (\%) AuNPs Room } \\
\text { Temperature }\end{array}$ & $\begin{array}{c}\text { AA (\%) AuNPs 50 } \\
{ }^{\circ} \mathbf{C}\end{array}$ \\
\hline Hyssop (Hyssopus officinalis) & $520 \mathrm{~nm}$ & $522 \mathrm{~nm}$ \\
\hline $\begin{array}{c}\text { European goldenrod (Solidago } \\
\text { virgaurea) }\end{array}$ & $531 \mathrm{~nm}$ & $535 \mathrm{~nm}$ \\
\hline Knotgrass (Polygonum aviculare) & $541 \mathrm{~nm}$ & $545 \mathrm{~nm}$ \\
\hline
\end{tabular}

\subsection{Kinetics of the Green Synthesized Noble Metallic Nanoparticles}

UV-Vis spectra were consequently recorded for all the three aqueous extracts and the corresponding green-synthesized noble metallic nanoparticles (AgNPs and AuNPs). As mentioned before, the simplest way to show that either AgNPs or AuNPs are obtained is the change in color of all the three aqueous extracts after adding either $\mathrm{AgNO}_{3}$ or $\mathrm{HAuCl}_{4}$ (Table 4).

Table 4. Colour of the green synthesized AgNPs and AuNPs.

\begin{tabular}{cccc}
\hline Crt. no. & $\begin{array}{c}\text { Hyssop (Hyssopus } \\
\text { officinalis) }\end{array}$ & $\begin{array}{c}\text { European goldenrod } \\
\text { (Solidago virgaurea) }\end{array}$ & $\begin{array}{c}\text { Knotgrass (Polygonum } \\
\text { aviculare) }\end{array}$ \\
\hline Aq. extract & Light violet & Light yellow & Green \\
\hline $\begin{array}{c}\text { AgNPs RT } \\
\begin{array}{c}\text { AgNPs 50 } \\
{ }^{\circ} \mathrm{C}\end{array}\end{array}$ & Light yellow-violetish & Dark yellow & Yellow-greenish \\
\hline $\begin{array}{c}\text { AuNPs } \\
\text { RT }\end{array}$ & Light violet & Dark yellow & Dark yellow \\
\hline $\begin{array}{c}\text { AuNPs } 50 \\
{ }^{\circ} \mathrm{C}\end{array}$ & Red-violet & Dark red & Dark red \\
\hline
\end{tabular}

UV-Vis spectra (Figure 1) were recorded at different time intervals ( $0 \mathrm{~s}, 5 \mathrm{~min}, 15 \mathrm{~min}, 30 \mathrm{~min}, 1$ $\mathrm{h}$ and $24 \mathrm{~h}$ ) to fully characterize the time-dependent stability of the green synthesized noble metallic nanoparticles [12]. In accordance with the polydispersity of the green-synthesized AgNPs, Figure 1 
clearly shows that the absorption peaks are broad, with a maximum between $432 \mathrm{~nm}$ for AgNPs at room temperature and 457 for AgNPs at $50{ }^{\circ} \mathrm{C}$ respectively.

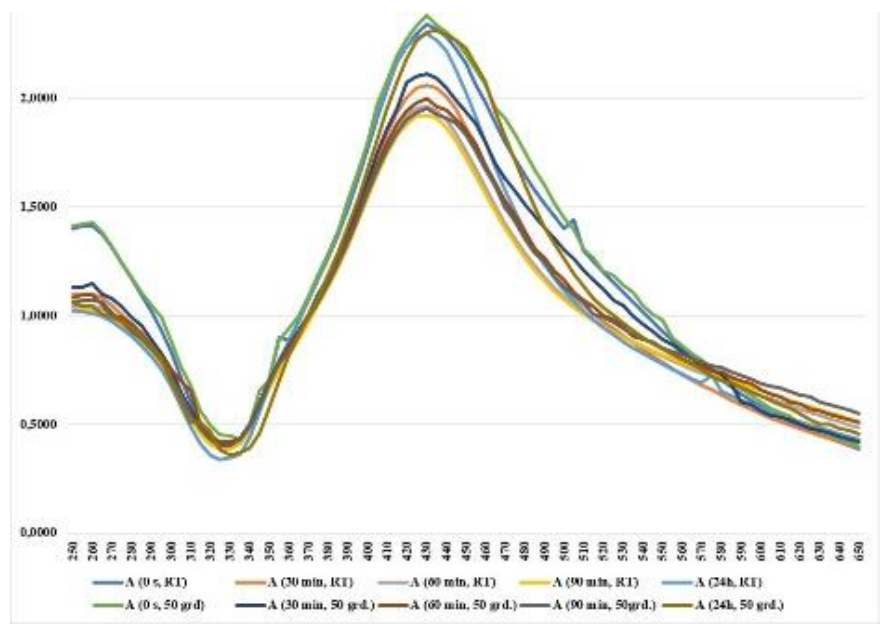

Figure 1. Kinetics of AgNPs green synthesized from plant extracts in both temperature conditions.

Figure 1 clearly highlights that once the reduction time increases the amount of greensynthesized AgNPs also increases, with a maximum after $24 \mathrm{~h}$.

\subsection{Fourier transform infrared spectroscopy (FTIR) results}

FTIR spectra allows the evaluation of all the functional groups in all the studied samples (aqueous extracts and noble metallic nanoparticles) and were recorded after the samples were dried. The strong band measured at $3300 \mathrm{~cm}^{-1}$ for the aqueous extract of Hyssop (Hyssopus officinalis), European goldenrod (Solidago virgaurea) and Knotgrass (Polygonum aviculare)) and its corresponding AgNPs shows the presence of alkynes. The medium absorption bands recorded between $2800-3000 \mathrm{~cm}^{-1}$ are characteristic for alkyl-methyl bonds and the clear band around 1460 $\mathrm{cm}^{-1}$ in all the aqueous extract is characteristic for the imidazole ring. The peak at $1200 \mathrm{~cm}^{-1}$ (present only in the aqueous extracts) is attributed to amides, proteins and enzymes and are absent in the FTIR spectra of corespondign gNPs, thus emphasizing the reduction of silver ions.

\subsection{Antioxidant activity results}

Antioxidant activity (AA, \%) of the green synthesized AgNPs was calculated according to the DPPH method and the results are fully described in Table 5 and compared to those of the aqueous extracts. It is obvious that, for all the green synthesized AgNPs, AA (\%) has increased values that those of the corresponding aqueous extracts and a comparison between AgNPs and AuNPs highlights that the antioxidant activities for all the green synthesized AgNPs are higher compared to AuNPs (Table 6).

Table 5. Antioxidant activity for the green synthesized AgNPs.

\begin{tabular}{cccc}
\hline Aqueous Extract & $\begin{array}{c}\text { AA (\%) of } \\
\text { Aqueous Extracts }\end{array}$ & $\begin{array}{c}\text { AA (\%) AgNPs Room } \\
\text { Temperature }\end{array}$ & $\begin{array}{c}\text { AA (\%) } \\
\text { AgNPs 50 }{ }^{\circ} \mathbf{C}\end{array}$ \\
\hline $\begin{array}{c}\text { Hyssop (Hyssopus } \\
\text { officinalis) }\end{array}$ & 81.98 & 92.92 & 91.09 \\
\hline $\begin{array}{c}\text { European goldenrod } \\
\text { (Solidago virgaurea) }\end{array}$ & 81.52 & 91.49 & 91.25 \\
\hline $\begin{array}{c}\text { Knotgrass (Polygonum } \\
\text { aviculare) }\end{array}$ & 82.05 & 90.78 & 91.09 \\
\hline
\end{tabular}


From Table 5 it is clear that the AA (\%) for the aqueous extracts have calculated values between 81.52 (Hyssop) and 82.05 (Knotgrass) and there are insignificant differences between the AgNPs green synthesized at room temperature and those at $50{ }^{\circ} \mathrm{C}$. Also, it can be concluded that in the case of Hyssop and European goldenrod, the green synthesis at room temperature gives better results in terms of antioxidant activity. 
Table 6. Antioxidant activity of aqueous extracts and AuNPs.

\begin{tabular}{cccc}
\hline Aqueous Extract & $\begin{array}{c}\text { AA (\%) of } \\
\text { Aqueous Extracts }\end{array}$ & $\begin{array}{c}\text { AA (\%) AuNPs Room } \\
\text { Temperature }\end{array}$ & $\begin{array}{c}\text { AA (\%) } \\
\text { AuNPs 50 }\end{array}$ \\
\hline $\begin{array}{c}\text { Hyssop (Hyssopus } \\
\text { officinalis) }\end{array}$ & 81.98 & 88.66 & 88.90 \\
\hline $\begin{array}{c}\text { European goldenrod } \\
\text { (Solidago virgaurea) }\end{array}$ & 81.52 & 88.69 & 89.98 \\
\hline $\begin{array}{c}\text { Knotgrass (Polygonum } \\
\text { aviculare) }\end{array}$ & 82.05 & 86.87 & 87.98 \\
\hline
\end{tabular}

Table 6 presents the results for AuNPs and it can be cocluded that, for all three plants, the green synthesis at $50{ }^{\circ} \mathrm{C}$ gives a higher $\mathrm{AA} \%$.

\subsection{Dynamic light scaterring (DLS) results}

Particle size is easily determined by measuring random changes of the intensity of light scattered from suspensions or solutions and this technique is briefly known as dynamic light scattering (DLS). All the green synthesized AgNPs and AuNPs were characterized by means of DLS and the results for AgNPs are described in Table 7. Also, zeta potential determinations were used to approximate the surface charge that allows a better understanding of the physical stability of the green synthesized AgNPs and AuNPs [13].

Table 7. DLS and seta potenatial for the green synthesized AgNPs.

\begin{tabular}{lclll}
\hline Crt. No. & Dm (d.nm) & P1...i (d.nm) $_{1}$ & PdI & PZ (mV) \\
\hline AgNPs-Hyssop & 61 & $\mathrm{P}_{1}=91 ; \mathrm{P}_{2}=11$ & 0.297 & -20.5 \\
\hline AgNPs-European goldenrod & 94 & $\mathrm{P}_{1}=474 ; \mathrm{P}_{2}=72$ & 0.551 & -26.3 \\
\hline AgNPs-Knotgrass & 159 & $\mathrm{P}_{1}=1492 ; \mathrm{P}_{2}=123$ & 0.543 & -15.4 \\
\hline
\end{tabular}

\section{Conclusions}

This paper describes the green synthesis of silver (AgNPs) and gold (AuNPs) nanoparticles from aqueous extracts of Hyssop (Hyssopus officinalis), European goldenrod (Solidago virgaurea) and Knotgrass (Polygonum aviculare), plants used with good results in traditional medicine for different purposes. The aqueous extracts were prepared following the cold infusion protocol from commercially available tea. The bioreduction of silver and gold ions was first observed from the visual change in color of the resulted colloidal solutions of AgNPs and AuNPs and is further highlighted by the UV-Vis spectra. All the absorptions recorded at $270 \mathrm{~nm}$ and $370 \mathrm{~nm}$ for all the three aqueous extracts can be assigned to phenolic acids and their derivatives. FTIR spectra allowed a proper evaluation of the functional groups in all the studied samples (aqueous extracts and noble metallic nanoparticles) and were recorded after the samples were dried. By analyzing the UV-Vis spectra recorded for AgNPs at different time intervals, we could conclude that once the reduction time increased, the amount of AgNPs also increased, exhibiting a maximum after $24 \mathrm{~h}$. Antioxidant activity, evaluated using the DPPH assay, showed increased values for AgNPs and AuNPs that those of the corresponding aqueous extracts and a comparison between AgNPs and AuNPs highlights that the antioxidant activities for all the green synthesized AgNPs are higher compared to AuNPs.

Author Contributions: Conceptualization, A.-A.S. and A.N.; methodology, A.-A.S., A.N., R.-M.I. and M.E.D.; physical-chemical investigations, A.-A.S., A.N. and M.E.D.; writing-original draft preparation, A.-A.S.; writing - review and editing, A.-A.S. and A.N.; visualization, M.E.D.; supervision, A.N. and R.-M.I. All authors have read and agreed to the published version of the manuscript.

Conflicts of Interest: The authors declare no conflict of interest. 


\section{References}

1. Singh, P.; Kim, I.J.; Zhang, D.; Yang, D.K. Biological synthesis of nanoparticles from plants and microorganisms. Trends Biotechnol. 2016, 34, 588-599.

2. Bhardwaj, B.; Singh, P.; Kumar, A.; Kumar, S.; Budwar, V. Eco-friendly greener synthesis of nanoparticles. Adv. Pharm. Bull. 2020, 10, 566-576.

3. Khan, I.; Saeed, K. Nanoparticles: Properties, applications and toxicities. Arabian J. Chem. 2017, 5, $255-260$.

4. Rauwel, P.; Küünal, S.; Ferdov, S.; Rauwel, E. A review on the green synthesis of silver nanoparticles and their morphologies studied via TEM. Adv. Mat. Sci. Eng. 2015, 8, 50-59.

5. Singh, H.; Du, J.; Singh, P.; Yi, T.H. Ecofriendly synthesis of silver and gold nanoparticles by Euphrasia officinalis leaf extract and its biomedical applications. Artif. Cells Nanomed. Biotechnol. 2018, 46,1163-1170.

6. Huo. Y.; Singh, P.; Kim, Y.J.; Soshnikova, V.; Kang, J.; Markus, J.; Ahn, S.; Castro-Aceituno, V.; Mathiyalagan, R.; Chokkalingam, M.; et al. Biological synthesis of gold and silver chloride nanoparticles by Glycyrrhiza uralensis and in vitro applications. Artif. Cells Nanomed. Biotechnol. 2018, 46, 303-312.

7. Zheljazkov, V.D.; Astatkie, T.; Hristov, A.N. Lavender and hyssop productivity, oil content, and bioactivity as a function of harvest time and drying. Ind. Crop Prod. 2012, 36, 222-228.

8. Szymura, M.; Szymura, T.H. Interactions between alien goldenrods (Solidago and Euthamia species) and comparison with native species in Central Europe. Flora-Morph. Distrib. Funct. Ecol. Plnts 2016, 218, 51-61.

9. Malavert, C.; Roberto, D.B.; Benech-Arnold, L. Temperature-Dependent regulation of induction into secondary dormancy of Polygonum aviculare L. seeds: A quantitative analysis. Ecol. Model 2017, 352, 128138.

10. Biswas, T.K.; Sarkar, S.M.; Yusoff, M.M.; Rahman, M.L. Synthesis and characterization of azobenzenebased gold nanoparticles for photo-switching properties. J. Mol. Liq. 2016, 214, 231-237.

11. Jeong, J.H.; Lee, J.W.; Kim, K.S.; Kim, J.-S.; Han, S.N.; Yu, C.Y.; Lee, J.K.; Kwon, Y.S.; Kim, M.J. Antioxidant and antimicrobial activities of extracts from a medicinal plant, Sea buckthorn. J. Korean Soc. Appl. Biol. Chem. 2010, 53, 33-38.

12. Aleksandrova, G.P.; Sukhov, B.G. Kinetics of the silver nanoparticles formation in the biopolymer matrix. Phys. Chem. Appl. Nanostruct. 2015, 25, 335-348.

13. Joseph, E.; Singhvi, G. Multifuntional nanocrystals for cancer therapy: A potential nanocarrier. Nanomat. Drug Deliv. Therapy 2019, 36, 91-116.

Publisher's Note: MDPI stays neutral with regard to jurisdictional claims in published maps and institutional affiliations.

(C) 2020 by the authors. Submitted for possible open access publication under the terms and conditions of the Creative Commons Attribution (CC BY) license (http://creativecommons.org/licenses/by/4.0/). 